\title{
On the use of mercury-coated tips in scanning electrochemical microscopy to investigate galvanic corrosion processes involving zinc and iron
}

\author{
Ricardo M. Souto ${ }^{\mathrm{a}, \mathrm{b}, *}$, Yaiza González-García ${ }^{\mathrm{a}}$, Dario Battistel ${ }^{\mathrm{c}}$, Salvatore Daniele ${ }^{\mathrm{c}}$ \\ a Department of Physical Chemistry, University of La Laguna, E-38200 La Laguna, Tenerife, Canary Islands, Spain \\ ${ }^{\mathrm{b}}$ Instituto Universitario de Materiales y Nanotecnologías, University of La Laguna, E-38200 La Laguna, Tenerife, Canary Islands, Spain \\ ${ }^{\mathrm{c}}$ Dipartimento di Scienze Molecolari e Nanosistemi, Università Cà Foscari Venezia, Calle Larga S. Marta, 2137, 30123 Venice, Italy
}

\section{A R T I C L E I N F O}

Article history:

Received 20 June 2011

Accepted 3 November 2011

Available online 11 November 2011

\section{Keywords:}

A. Zinc

A. Iron

C. Anodic dissolution

C. Oxygen reduction

\begin{abstract}
A B S T R A C T
The corrosion processes related to zinc dissolution that take place in an iron-zinc galvanic pair exposed to a chloride solution were investigated by scanning electrochemical microscopy (SECM) using a mercury-coated platinum microelectrode as SECM tip. Both the release of zinc ions and the consumption of dissolved oxygen that occur in separate sites at the iron-zinc galvanic pair were monitored. Zinc ion quantification could be performed by stripping the zinc metal collected at the Hg-coated tip using linear sweep voltammetry.
\end{abstract}

(c) 2011 Elsevier Ltd. All rights reserved.

\section{Introduction}

In situ information on the chemistry and structure at the metal/ electrolyte interface is necessary to know the corrosion behavior of metals and alloys in aqueous environments, and to develop and test efficient protection strategies for longer corrosion resistance of the materials. Nowadays, there is a quite large number of techniques that can be used for corrosion studies, and the choice of the most suitable one to be employed in the investigation depends on various factors, including the surface condition of the materials, dimensions of films and layers on the metal surfaces, and physicochemical characteristics of the aggressive environment. In this way, structural and chemical composition data, as well as surface imaging have been achieved, though, often, measurement procedures involved ex situ operations, thus generally quite different from those met by the materials in their environment. Moreover, time-resolved analysis is very difficult at their best, thus making the dynamics of structure modifications produced by the corrosion processes practically impossible to follow. The advent of scanning electrochemical techniques has opened up new opportunities in this field, and among them, scanning electrochemical microscopy (SECM) is conceiting most prospects due to its versatility to examine, with high spatial resolution, the surface topography and the electrochemical reactivity of many metal substrates subjected to corrosion processes [1-4]. Despite the variety of systems charac-

\footnotetext{
* Corresponding author at: Department of Physical Chemistry, University of La Laguna, E-38200 La Laguna, Tenerife, Canary Islands, Spain. Tel.: +34 9223180 67; fax: +349223180 02 .

E-mail address: rsouto@ull.es (R.M. Souto).
}

terized by this technique, major limitations have been found for the investigation of a number of technologically interesting metal materials, such as zinc and magnesium. In fact, direct monitoring of the corresponding metal ions could not be investigated because either their corresponding standard redox potentials occur in the range of hydrogen evolution on platinum microelectrodes, which are usually employed as the SECM probe, or they would require the electroreduction of the metal ions to the zero oxidation state, thus effectively modifying the electrochemical response of the SECM tip. On the other hand, those materials are receiving major attention because of lightweighting in areas of automotive and aerospace applications, or as components for active corrosion protection through galvanic coupling and cathodic protection mechanisms. In fact, zinc has been employed in the galvanizing of steels since long ago, but it is also present in modern coating formulations for metal protection designed for offshore conditions, where zinc-rich primers are widely used.

Therefore, the development of operation procedures based on scanning electrochemical techniques, opening ways to investigate zinc reactivity in situ, is currently a topic of major interest. This is even more the case of scanning electrochemical microscopy, since direct monitoring of zinc dissolution has not been possible yet with the use of typical SECM tips [5,6]. The introduction of $\mathrm{Hg}$ microelectrodes as SECM tips has opened new possibilities in corrosion research [7]. In fact, Hg probes offer a wider negative potential range than bare platinum tips allowing for the reduction of zinc ions at the tip to be investigated with low interference from oxygen reduction or hydrogen evolution from aqueous solutions [7]. Hg microelectrodes can be fabricated by electrodeposition of liquid mercury onto Pt microdisks [8-11], and adopt a sphere cap 
geometry, whose size depends on the plating time. Theory to predict diffusion-controlled steady state currents [12-14] and approach curves at sphere-cap tips for both negative and positive feedback conditions [15] is also available.

The objective of this contribution is to assess the ability of SECM coupled to hemispherical SECM tips for monitoring of galvanic coupling reactions involving zinc dissolution. In this work, proof of concept is illustrated for a model zinc-iron galvanic couple immersed in a naturally-aerated aqueous sodium chloride solution.

\section{Experimental}

The model iron-zinc bimetallic sample consisted of squares with ca. $1 \times 1 \mathrm{~mm}^{2}$ from each metal to form the testing metal substrates, and they were embedded into an epoxy resin sleeve, such that only the square end surface forms the testing surface. The separation between them was approximately $1.2 \mathrm{~mm}$. Iron and zinc were connected electrically at the back of the epoxy mount to form a galvanic couple. $99.95 \%$ pure zinc and $99.5 \%$ pure iron, both supplied as sheets of thickness $1 \mathrm{~mm}$ by Goodfellow Materials Ltd. (Cambridge, UK), were employed. The mounts with the samples were ground with silicon carbide paper down to 1200 grit, washed thoroughly with Millipore deionised water, dried with acetone and finally surrounded laterally by Sellotape, thus creating a small container for the test electrolyte solution.

The platinum microdisks, which served as the substrates for mercury deposition, were prepared by sealing wires $25 \mu \mathrm{m}$ diameter into glass capillaries, which were produced with a conical shape. Prior to mercury deposition, the exposed microdisks were polished with graded alumina of different sizes on a polishing microcloth. Deposition of mercury onto the platinum microdisks was carried out under potentiostatic control in $5 \mathrm{mM}$ $\mathrm{Hg}_{2}\left(\mathrm{NO}_{3}\right)_{2}+0.1 \mathrm{M} \mathrm{KNO}_{3}$ acidified at pH 1 with $\mathrm{HNO}_{3}$ [11]. The mercury microelectrode aspect ratio is described by the parameter $H=h / a$ (i.e. the sphere-cap height $(h)$ to the electrode basal radius (a) ratio) as shown in Fig. 1. Hexammine ruthenium (III) was added to the test electrolyte for the characteristic parameters of the microelectrode to be determined prior to its use as tip in scanning electrochemical microscopy. The electrochemical cell was completed using an $\mathrm{Ag} / \mathrm{AgCl} / \mathrm{KCl}$ (sat.) reference electrode, and a platinum wire as the counter electrode. Tests were carried out in aqueous $0.1 \mathrm{M} \mathrm{NaCl}$ solution open to air and left at ambient temperature.

A home built SECM apparatus (previously described in Ref. [16]) was employed. In brief, the $3 \mathrm{D}$ positioning device consisted of a set of three step motor stages with a $0.1 \mu \mathrm{m}$ resolution. The data

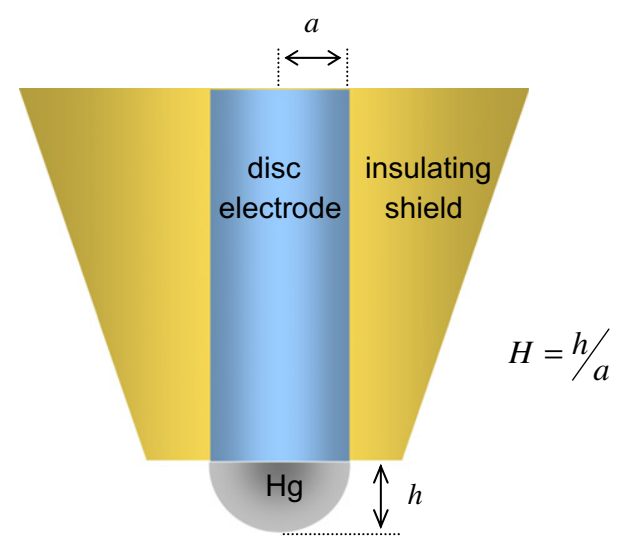

Fig. 1. Sketch that represents the sphere-cap geometry of the mercury deposited on a platinum microdisk electrode and the characteristic parameters. acquisition was performed by a PCI-6035E Multifunction I/O with a Lab View software (National Instruments). Electrochemical operation was achieved using a PAR 175 function generator associated with a current amplifier Keithley 428. For the sake of normalization, the dimensionless tip current, $i / i_{\text {lim }}$, and the dimensionless distance between the sample and the tip, $L=d / a$, are employed throughout.

Linear sweep voltammetry was performed using a PAR 283 potentiostat/galvanostat controlled with a personal computer via the M270 PAR software.

\section{Results and discussion}

\subsection{Characterization of the mercury microelectrode}

The microelectrodes fabricated according to the preparation procedures described in Section 2, were subsequently subjected to electrochemical characterization in order to determine their characteristic parameters. The effective radius $(a)$ of the basal platinum microelectrode was determined from the steady state limiting current $\left(i_{\text {lim }}\right)$ recorded in the bulk solution of $1 \mathrm{mM}$ $\mathrm{Ru}\left(\mathrm{NH}_{3}\right)_{6} \mathrm{Cl}_{3}$, by using Eq. (1) [17]:

$i_{\text {lim }}=4 n F D c^{b} a$

where $n$ is the number of electrons, $D$ is the diffusion coefficient $\left(D=7.0 \times 10^{-6} \mathrm{~cm}^{2} \mathrm{~s}^{-1}[18]\right), c^{b}$ is the bulk concentration. Fig. $2 \mathrm{~A}$ depicts the typical cyclic voltammogram, which exhibits the expected sigmoidal shape that is characteristic of a microelectrode working under steady-state conditions. The $R G$ value of the disk microelectrodes was determined by fitting theoretical SECM approach curves to the experimental ones recorded under purely diffusion-controlled conditions. Fig. 2B shows a selected SECMapproach curve obtained during the approach of the Pt microelectrode towards an insulating substrate. Good agreement between the experimental data and the theoretical curve for negative feedback [19] occurred for an $R G$ value equal to 5 .

Analogously, the shape and geometric parameters of the sphere-cap microelectrode was checked by voltammetry using the same redox couple. Fig. 3A depicts a typical cyclic voltammogram measured in the hexammine ruthenium (III) containing solution, and the measured limiting current was in agreement with that predicted by Eq. (2):

$i_{\text {lim }}=k n F D c^{b} a$

where $k$ is a geometric coefficient that depends on the sphere cap height. In general, for the deposition time employed in this work (about $10 \mathrm{~min}$ ), the sphere-cap produced had a height $h$ equal to the radius of the Pt disk, that is $H=1$. Comparison of the cyclic voltammograms displayed in Figs. 2A and 3A leads to the observation that a larger limiting current is measured at the sphere cap mercury microelectrode than the corresponding platinum microelectrode, which is an indication of the increase of the electrode surface after the $\mathrm{Hg}$ deposition.

On the other hand, the mercury electrode was also checked by comparing the recorded SECM-approach curve towards an insulating substrate with the theoretical curves obtained from the application of Eq. (3):

$I(L)=\frac{1}{K_{1}+K_{2} / L+K_{3} \exp \left(K_{4} / L\right)}$

where the coefficients $K_{i}$ are adjustable parameters which depend on the $R G$ value of the disk electrode and on the $H(=h / a)$ value of the sphere-cap [15]. Fig. 3B shows a selected experimental curve and the theoretical approach corresponding to a sphere-cap of $H=1$ and a $R G$ value about 5 . This $R G$ value agreed well with the 



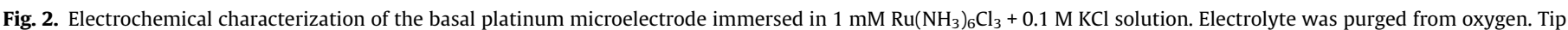

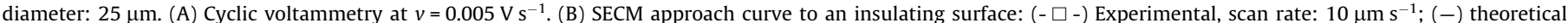

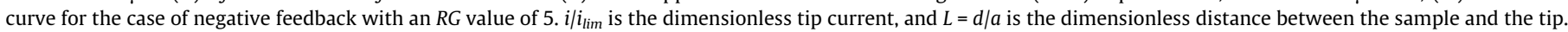
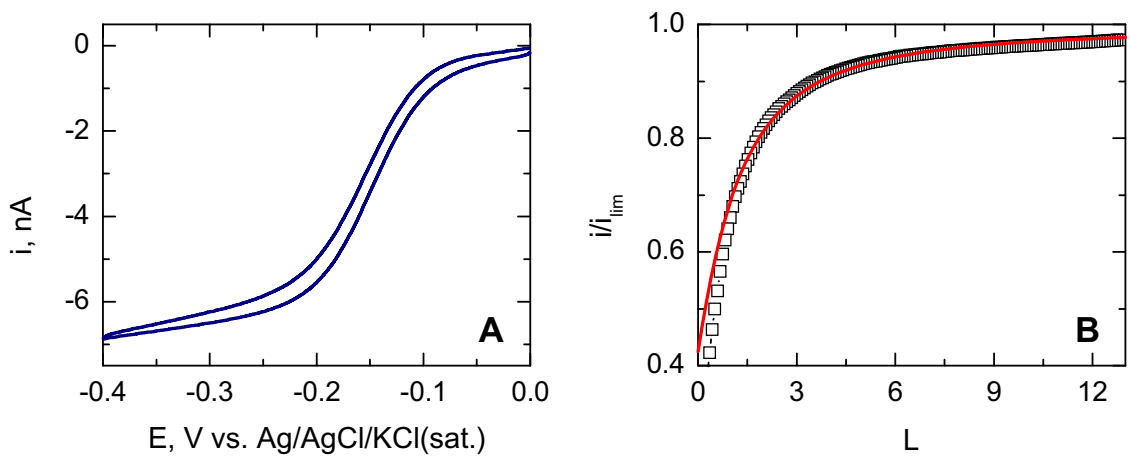

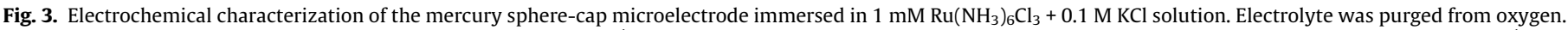

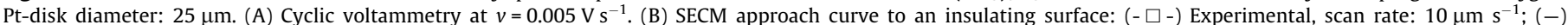

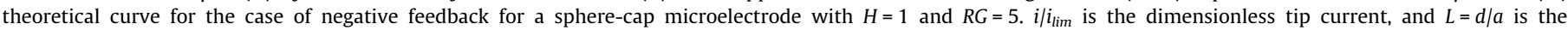
dimensionless distance between the sample and the tip.

experimental data and it was obtained on the Pt disk microelectrode prior to mercury deposition (cf. Fig. 2B).

\subsection{Monitoring $\mathrm{Zn}^{2+}$ ions from the galvanic corrosion of a $\mathrm{Fe}-\mathrm{Zn}$ couple}

In previous work, concerning the corrosion behavior of isolated zinc and iron wires, it was shown that on each metal surface both the anodic and cathodic sites, where the metal dissolution and the oxygen reduction, respectively, occurred, could be visualized [6]. Galvanic coupling of the iron and zinc wires, separated by a region of insulating epoxy resin, leads to the physical separation of the corrosion half cells. Under these conditions, the anodic process takes place on the zinc metal, while the cathodic reaction happens at the iron surface [6]. The distribution of these reactions was detected in situ by scanning the $\mathrm{Hg}$ microelectrode polarized at $-1.20 \mathrm{~V}$ vs. $\mathrm{Ag} / \mathrm{AgCl} / \mathrm{KCl}$ (sat.), where the reduction of both $\mathrm{Zn}(\mathrm{II})$ species and molecular oxygen occurs [7]. SECM line scans were performed across the surface of zinc and iron by positioning the $\mathrm{Hg}$ tip at various distances above the substrate investigated. The position of the SECM tip was initially established by using the approach curves performed above the insulating layer of the epoxy resin using oxygen as redox mediator as shown in Fig. 4.

Fig. 5 displays a set of line scans across the two metals obtained accordingly. The generation of soluble $\mathrm{Zn}$ (II) species due to the corrosion of the zinc is observed as a large negative current when the tip passed over the zinc sample. That is, the cathodic currents measured at the tip grew significantly when the tip was scanned over the zinc metal. On the other hand, the consumption of oxygen in the cathodic reaction that occurs on the iron specimen was de-

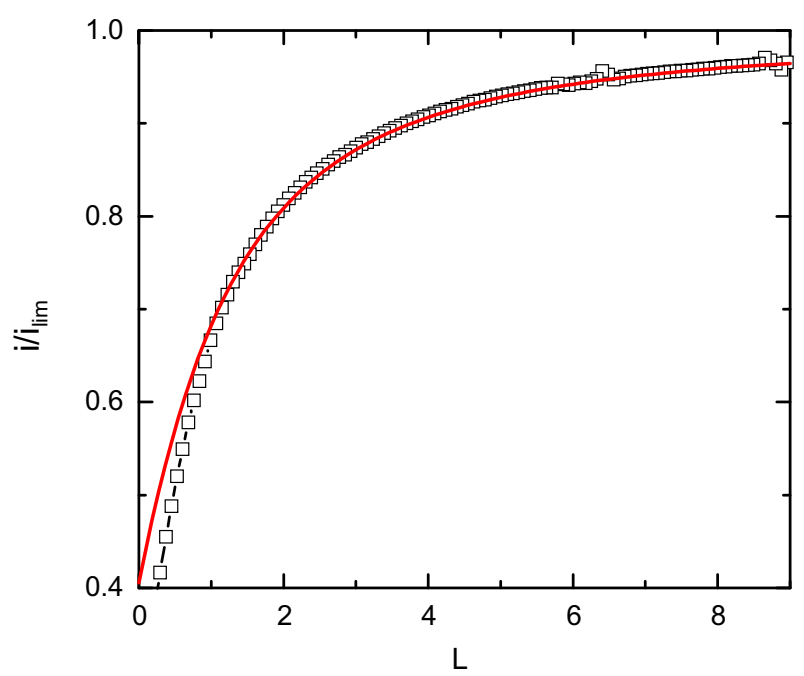

Fig. 4. (- $\square$-) SECM approach curve to an insulating surface measured at the $\mathrm{Hg}$ sphere-cap microelectrode immersed in $0.1 \mathrm{M} \mathrm{NaCl}$ solution. The reduction of the oxygen dissolved in the solution was employed as the redox mediator reaction. Scan rate: $10 \mu \mathrm{m} \mathrm{s}^{-1}$. (-) Theoretical approach curve calculated for a negative feedback condition at a sphere-cap microelectrode with $H=1$ and $R G=5$. $i / i_{\text {lim }}$ is the dimensionless tip current, and $L=d / a$ is the dimensionless distance between the sample and the tip.

tected from the measurement of smaller faradaic currents at the tip than the corresponding background values. The reason for the latter is that oxygen is electroreduced at the cathodic sites occur- 


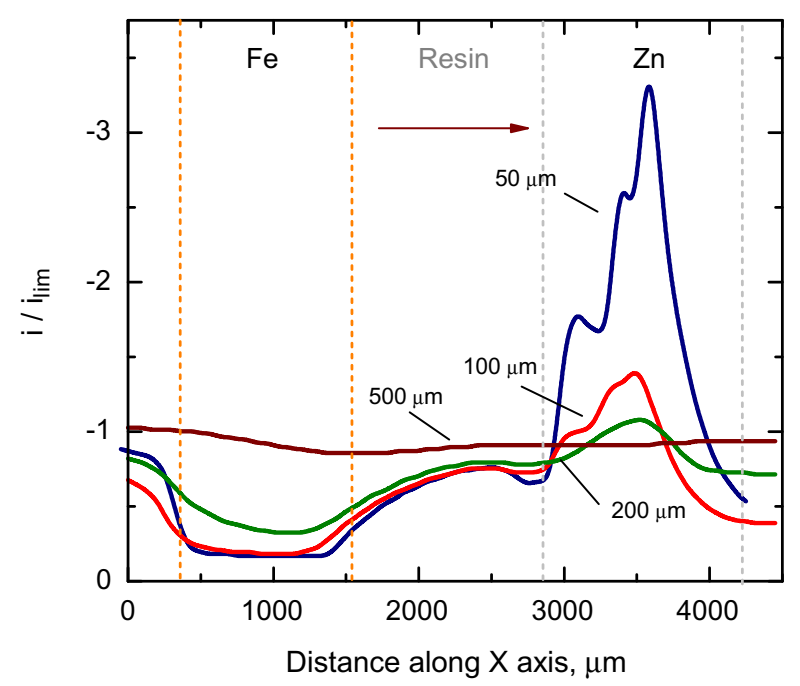

Fig. 5. Scan lines of a sphere-cap tip traveling above an iron-zinc galvanic pair after immersion in $0.1 \mathrm{M} \mathrm{NaCl}$. The plots were measured for different tip-substrate distances as indicated in the graph. Tip potential: $-1.20 \mathrm{~V}$ vs. $\mathrm{Ag} / \mathrm{AgCl} / \mathrm{KCl}$ (sat.); sphere-cap parameters: $H=1, R G=5$. The arrow indicates the direction of tip movement. $i / i_{\text {lim }}$ is the dimensionless tip current.

ring on iron, and therefore the amount of dissolved oxygen remaining in the electrolyte above this metal is diminished. Zinc dissolution in the galvanic pair was found to be spread, though not uniformly, over the whole area of the metal, conversely to what happened when isolated zinc was exposed to the same aggressive environment (Fig. 6). In the latter case, both the anodic and cathodic reactions responsible for the corrosion process were located over the same metal, whereas in the galvanic couple each of the two reactions occurred on a different metal. In Fig. 5, it is also worth noting that the cathodic current above the zinc sample is not homogeneously distributed but increases passing from the region closest to iron towards the center of the sample and then decreases drastically towards the other end of the sample. This feature is related to the tendency of zinc to develop pits on its surface during its corrosion in $0.1 \mathrm{M} \mathrm{NaCl}$, and this result agrees well

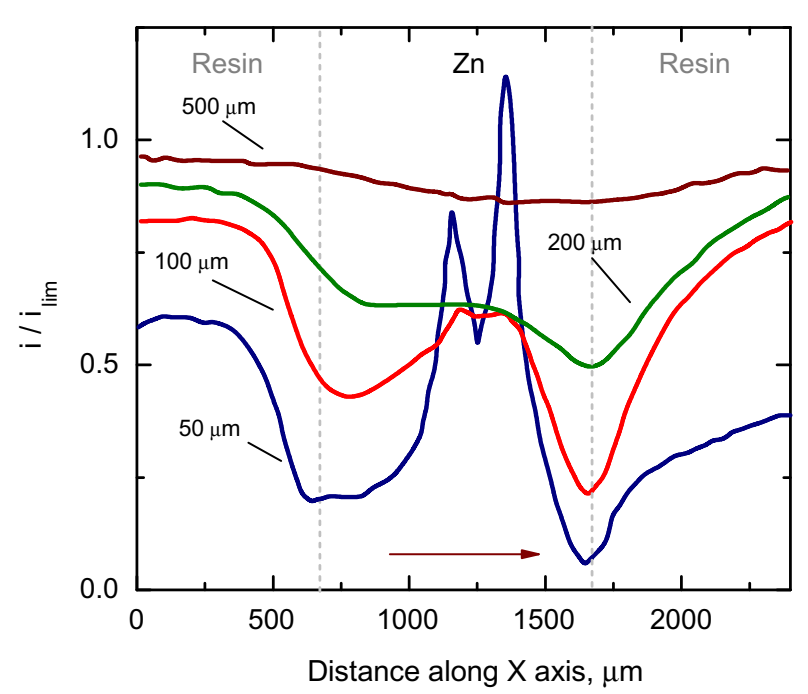

Fig. 6. Scan lines of a hemispherical mercury tip traveling above a zinc sample after immersion in $0.1 \mathrm{M} \mathrm{NaCl}$. The plots were measured for different tip-substrate distances as indicated in the graph. Tip potential: $-1.20 \mathrm{~V}$ vs. $\mathrm{Ag} / \mathrm{AgCl} / \mathrm{KCl}$ (sat.); sphere-cap parameters: $H=1, R G=5$. The arrow indicates the direction of tip movement. $i / i_{\text {lim }}$ is the dimensionless tip current. with previous observations derived from the measurement of ionic currents departing from the metal using the scanning vibrating electrode technique (SVET) [6]. Conversely, the oxygen depletion above the iron surface occurred almost uniformly because no preferential sites for this cathodic reaction are established on this metal, again closely matching SVET observations [6].

Scan lines recorded at different tip-substrate distances, also included in Fig. 5, shows that the ability of the technique to spatially resolve the highly localized anodic process occurring on the zinc metal is reduced as the tip-substrate distance is increased. This feature is a consequence of the diffusion of the ions from the source at the surface into the bulk electrolyte, and therefore the currents become less intense and more distributed laterally as the microelectrode is moved away from the metal.

The effect of the diffusion of the generated $\mathrm{Zn}$ (II) ions into the electrolytic solution from the zinc sample could also be investigated from the stripping of the zinc accumulated in the $\mathrm{Hg}$ electrode during the previous scan line. The corresponding stripping voltammetric waves for their oxidation are shown in Fig. 7. They were recorded at different electrode-substrate distances immediately after the measurement of the scan lines. It can be observed that the current signals due to metal stripped from the tip depended on the tip-substrate distance. Therefore the latter is a critical parameter that affects the lateral resolution of the concentration profiles of species generated at a corroding substrate. As for the shape of the stripping voltammograms displayed in Fig. 7, which present various peaks at different potentials, it can be attributed to a complex electrode process pathway involving also oxygen present in the solution, which is also reduced within the potential region explored. To confirm that the multiple stripping peaks are related to the oxidation of amalgamated zinc, test experiments were performed in $\mathrm{Zn}\left(\mathrm{NO}_{3}\right)_{2}$ aerated solutions in a conventional electrochemical cell. A typical stripping voltammogram thus obtained is shown in Fig. 8. It is evident that multiple peaks are also observed in the test solution, thus confirming that the linear sweep stripping peaks recorded in the SECM measurements (Fig. 7) belongs to the metallic zinc accumulated in the mercury layer during the line scan. The concentration profile of zinc ions diffusing from the zinc surface towards the bulk solution was also estimated using a calibration plot based on the charge in-

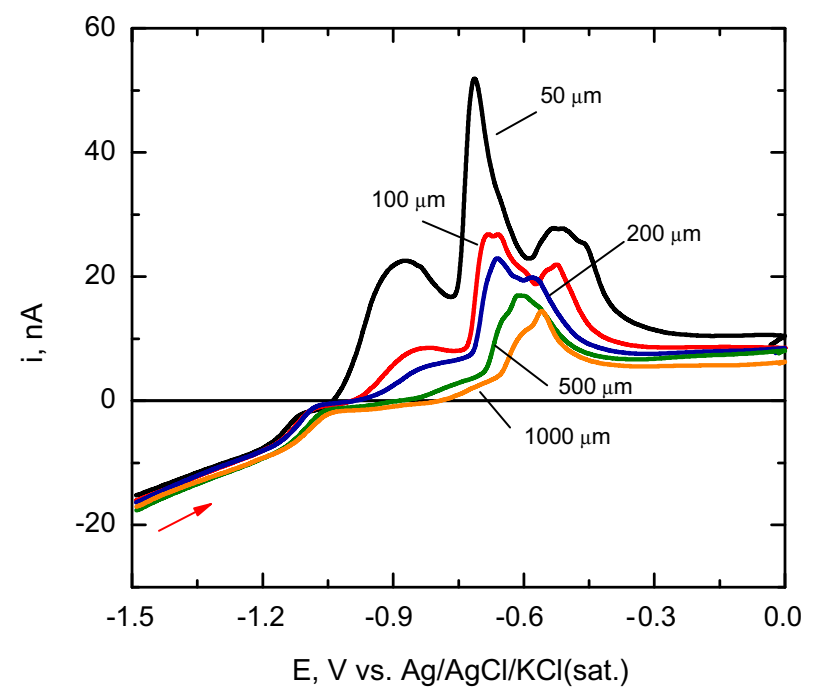

Fig. 7. Anodic stripping voltammograms of the zinc accumulated in the hemispherical mercury tip during the measurement of the scan lines depicted in Fig. 5. $v=0.05 \mathrm{~V} \mathrm{~s}^{-1}$. The distances in the plot correspond to the height of the tip above the substrate employed to record the corresponding scan lines over the iron-zinc galvanic pair. Electrolyte: $0.1 \mathrm{M} \mathrm{NaCl}$. Sphere-cap parameters: $H=1, R G=5$. 


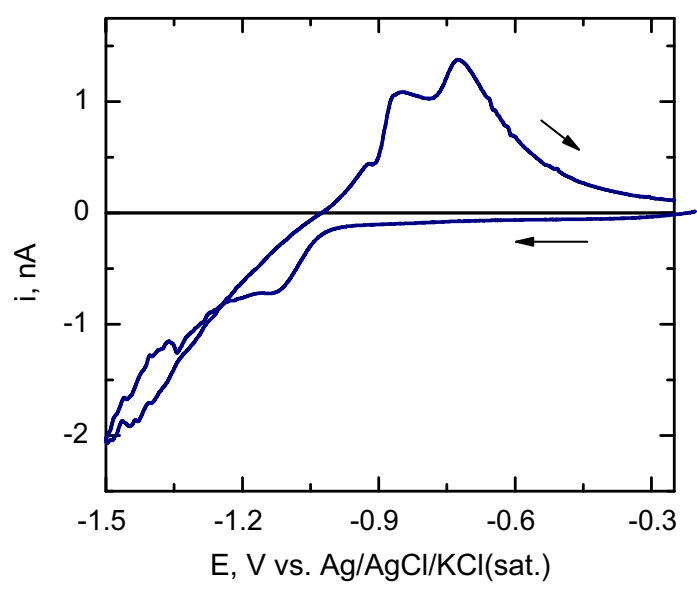

Fig. 8. Cyclic voltammogram recorded at a hemispherical mercury tip in the bulk of a $0.1 \mathrm{mM} \mathrm{Zn}\left(\mathrm{NO}_{3}\right)_{2}+0.1 \mathrm{M} \mathrm{NaCl}$ aerated solution. $v=0.02 \mathrm{~V} \mathrm{~s}^{-1}$.

volved in the stripping voltammograms [20]. In this way, it was established that when the tip was positioned at $50 \mu \mathrm{m}$ above the zinc sample, the concentration of zinc (II) was $1.7 \mathrm{mM}$; it decreased down to $0.7 \mathrm{mM}$ at $1000 \mu \mathrm{m}$.

\subsection{Discussion}

To our knowledge, the modification of microelectrode tips in SECM for the investigation of corrosion processes of active metals such as zinc, which cannot be further electrooxidized, has not been proposed before. Effectively it may mean that scanning electrochemical microscopy can be used for the detection of corroding metals with redox potentials so negative that the current signals due to their reductions overlap with those due to either oxygen reduction or hydrogen evolution from aqueous solutions, which was not possible with conventional microelectrode tips. Other drawbacks that have been overcome with the proposed method are related to the fact that the reduction of the metal ions on the solid electrode surface does not lead to change of the active area anymore, whereas the formation of a new metallic phase or oxide species eventually blocked the activity of the electrode surface of a platinum tip. Furthermore, using the mercury microelectrode as a SECM tip, a wider negative potential range becomes available, while the effects due to the oxygen reduction are somewhat limited. In fact on $\mathrm{Hg}$ the oxygen reduction occurs in two two-electron processes leading to hydrogen peroxide and water.

Therefore, scanning electrochemical microscopy can now be employed to investigate a number of corroding systems of major technological interest such as galvanized materials, zinc-rich coatings, and lightweight alloys, which could not be characterized with this technique unless operated in non-aqueous environments $[21,22]$. The in situ operation and electrochemical versatility of SECM will thus contribute to the understanding of corrosion reactions and protection mechanisms in addition to the valuable information provided until now almost exclusively by ex situ techniques such as the scanning Kelvin probe (SKP) [23-26], or by the determination of current fluxes of ionic species in the electrolyte phase provided by the scanning vibrating electrode technique (SVET) and related methods [6,27-33], which are blind to uncharged species and often operate at greater distances from the surface of the investigated material.

\section{Conclusions}

Mercury microelectrodes can be employed in scanning electrochemical microscopy to detect both the release of zinc(II) ions and the consumption of dissolved oxygen that occurs in the galvanic corrosion of a zinc-iron pair in aqueous solutions without interference from hydrogen evolution.

Dissolution of reduced zinc metal within the mercury layer avoids problems related to chemical and size changes of the tip due to the metal nucleation and growth process, a phenomenon that is typically encountered on solid SECM tips. And sensitive concentration profiles originated by dissolving zinc species from the metal could be determined by stripping voltammetry at the $\mathrm{Hg}$ microelectrode tip.

\section{Acknowledgements}

The authors are grateful to the Spanish Ministry of Science and Innovation (MICINN, Madrid) and the Italian Ministry of Universities and Research (MIUR, Rome) for the grant of a Collaborative Research Programme between Spain and Italy (Acción Integrada No. HI2004-0297) to fund this work. Y.G.G. is grateful to the University of La Laguna and Cajacanarias for the award of a doctoral grant.

\section{References}

[1] S.E. Pust, W. Maier, G. Wittstock, Investigation of localized catalytic and electrocatalytic processes and corrosion reactions with scanning electrochemical microscopy (SECM), Z. Phys. Chem. 222 (2008) 1463-1517.

[2] L. Niu, Y. Yin, W. Guo, M. Lu, R. Qin, S. Chen, Application of scanning electrochemical microscope in the study of corrosion of metals, J. Mater. Sci. 44 (2009) 4511-4521.

[3] Y. González-García, J.J. Santana, J. González-Guzmán, J. Izquierdo, S. González, R.M. Souto, Scanning electrochemical microscopy for the investigation of localized degradation processes in coated metals, Prog. Org. Coat. 69 (2010) $110-117$.

[4] R.M. Souto, S. Lamaka, S. González, Uses of scanning electrochemical microscopy in corrosion research, in: A. Méndez-Vilas, J. Díaz (Eds.), Microscopy: Science, Technology, Applications and Education, vol. 3, Formatex Research Center, Badajoz, 2010, pp. 1769-1780.

[5] R.M. Souto, Y. González-García, S. González, In situ monitoring of electroactive species by using the scanning electrochemical microscope. Application to the investigation of degradation processes at defective coated metals, Corros. Sci. 47 (2005) 3312-3323.

[6] A.M. Simões, A.C. Bastos, M.G. Ferreira, Y. González-García, S. González, R.M. Souto, Use of SVET and SECM to study the galvanic corrosion of an iron-zinc cell, Corros. Sci. 49 (2007) 726-739.

[7] S. Daniele, M.A. Baldo, C. Bragato, Recent development in stripping analysis on microelectrodes, Curr. Anal. Chem. 4 (2008) 215-228.

[8] K.R. Wehmeyer, R.M. Wightman, Cyclic voltammetry and anodic stripping voltammetry with mercury ultramicroelectrodes, Anal. Chem. 57 (1985) 19891993.

[9] A.S. Baranski, Rapid anodic stripping analysis with ultramicroelectrodes, Anal. Chem. 59 (1987) 662-666.

[10] S. Daniele, M.A. Baldo, P. Ugo, G.A. Mazzocchin, Determination of heavy metals in real samples by anodic stripping voltammetry with mercury microelectrodes. Part 1: Application to wine, Anal. Chim. Acta 219 (1989) 918.

[11] M.A. Baldo, S. Daniele, M. Corbetta, G.A. Mazzochin, Performance of platinumbased spherical mercury microelectrodes in cyclic voltammetry and stripping analysis, Electroanalysis 7 (1995) 980-986.

[12] A.M. Bond, K.B. Oldham, C.G. Zoski, Steady-state voltammetry, Anal. Chim. Acta 216 (1989) 177-230.

[13] K.B. Oldham, Steady-state microelectrode voltammetry as a route to homogeneous kinetics, J. Electroanal. Chem. 313 (1991) 3-16.

[14] S. Daniele, I. Ciani, D. Battistel, Effect of the insulating shield thickness on the steady-state diffusion-limiting current of sphere cap microelectrodes, Anal. Chem. 80 (2008) 253-259.

[15] G. Lindsey, S. Abercrombie, G. Denuault, S. Daniele, E. De Faveri, Scanning electrochemical microscopy: approach curves for sphere-cap scanning electrochemical microscopy tips, Anal. Chem. 79 (2007) 2952-2956.

[16] I. Ciani, S. Daniele, C. Bragato, Stability of mercury-coated platinum microelectrodes upon touching a solid surface in scanning electrochemical microscopy (SECM) experiments, Electrochem. Commun. 5 (2003) 354-358.

[17] Y. Saito, A theoretical study on the diffusion current at the stationary electrodes of circular and narrow band types, Rev. Polarogr. 15 (1968) 177187.

[18] P. Sun, Z. Zhang, J. Guo, Y. Shao, Fabrication of nanometer-sized electrodes and tips for scanning electrochemical microscopy, Anal. Chem. 73 (2001) 53465351.

[19] A.J. Bard, M.V. Mirkin (Eds.), Scanning Electrochemical Microscopy, Marcel Dekker, New York, 2001.

[20] S. Daniele, I. Ciani, M.A. Baldo, C. Bragato, Application of sphere cap mercury microelectrodes and scanning electrochemical microscopy (SECM) for heavy 
metal monitoring at solid/solution interfaces, Electroanalysis 19-20 (2007) 2067-2076.

[21] I. Serebrennikova, H.S. White, Scanning electrochemical microscopy of electroactive defect sites in the native oxide film on aluminium, Electrochem. Solid State Lett. 4 (2001) B4-B6

[22] I. Serebrennikova, S. Lee, H.S. White, Visualization and characterization of electroactive defects in the native oxide film on aluminium, Faraday Discuss. 121 (2002) 199-210.

[23] A. Tahara, T. Kodama, Potential distribution measurement in galvanic corrosion of Zn/Fe couple by means of Kelvin probe, Corros. Sci. 42 (2000) 655-673.

[24] A.K. Neufeld, I.S. Cole, A.M. Bond, S.A. Furman, The initiation mechanism of corrosion of zinc by sodium chloride particle deposition, Corros. Sci. 44 (2002) 555-572.

[25] E.P. Whyte, J.M. Sykes, Behaviour of a zinc-iron bimetallic couple coated with poly-vinyl butyral lacquer during intermittent exposure to salt solution, Corros. Sci. 49 (2007) 3361-3380.

[26] A.P. Yadav, H. Katayama, K. Noda, H. Masuda, A. Nishikata, T. Tsuru, Effect of Fe-Zn alloy layer on the corrosion resistance of galvanized steel in chloride containing environments, Corros. Sci. 49 (2007) 3716-3731.

[27] K. Ogle, S. Morel, D. Jacquet, Observation of self-healing functions on the cut edge of galvanized steel using SVET and pH microscopy, J. Electrochem. Soc. 153 (2006) B1-B5.
[28] R.M. Souto, Y. González-García, A.C. Bastos, A.M. Simões, Investigating corrosion processes in the micrometric range: a SVET study of the galvanic corrosion of zinc coupled with iron, Corros. Sci. 49 (2007) 4568-4580.

[29] D.-L. Zhang W. Wang, Y. Li, An electrode array study of electrochemica inhomogeneity of zinc in zinc/steel couple during galvanic corrosion, Corros. Sci. 52 (2010) 1277-1284.

[30] M. Yan, V.J. Gelling, B.R. Hinderliter, D. Battocchi, D.E. Tallman, G.P. Bierwagen, SVET method for characterizing anti-corrosion performance of metal-rich coatings, Corros. Sci. 52 (2010) 2636-2642.

[31] A.C. Bastos, M.G. Taryba, O.V. Karavai, M.L. Zheludkevich, S.V. Lamaka, M.G.S Ferreira, Micropotentiometric mapping of local distributions of $\mathrm{Zn}^{2+}$ relevant to corrosion studies, Electrochem. Commun. 12 (2010) 394-397.

[32] F. Thébault, B. Vuillemin, R. Oltra, C. Allely, K. Ogle, Modeling bimetallic corrosion under thin electrolyte films, Corros. Sci. 53 (2011) 201-207.

[33] S.V. Lamaka, M. Taryba, M.F. Montemor, H.S. Isaacs, M.G.S. Ferreira, Quasisimultaneous measurements of ionic currents by vibrating probe and $\mathrm{pH}$ distribution by ion-selective microelectrode, Electrochem. Commun. 13 (2011) 20-23. 